\title{
Experimental Study of Inorganic Binder Stable Chromium Slag Applied to the Base Course
}

\author{
Jianbo Han \\ Research Institute of Highway \\ Ministry of Transport \\ Beijing, China \\ Key Laboratory of Road Structure \& Material \\ Ministry of Transport \\ People's Republic of China \\ School of Civil Engineering \\ ShenYang Jianzhu University \\ Liaoning, China \\ hanjianbo_good@163.com \\ Jiahuan Yu \\ School of Civil Engineering \\ ShenYang Jianzhu University \\ Liaoning, China \\ 826125581@qq.com
}

\author{
Peng Peng
Institute of Highway \\ Peng Peng
Research Institute of Highway \\ Ministry of Transport \\ Beijing, China \\ 424751349@qq.com
}

\author{
Ying Liu \\ Research Institute of Highway \\ Ministry of Transport \\ Beijing, China \\ 87231376@qq.com
}

\begin{abstract}
Choosing cement and lime as inorganic binder, stabled chromium slag and then did the tests of the compaction, unconfined compressive strength and the stability for studying it as road base material, perfected the base material mixture ratio design and comparatively analyzed its mechanical properties and environmental indicators.Tests and analysis show that cement stable chromium slag when inorganic binder used alone on the basis of the optimal mixture ratio, which is better to meet the using performance requirements as road base materials; Mechanical performance offered by lime stable chromium slag is a bit weak, while it can be obtained extra stability effect to plus a small amount of cement or fly ash.
\end{abstract}

Keywords:Unconfined compressive strength; Chromium slag; Stable; Inorganic binder;

\section{INTRODUCTION}

The base course of road, below the surface, is mainly bear the vehicle load that passed down from the surface and spread to the load of roadbed [1]. Cement stable gravel, two ash stable gravel and macadam mixture, which is widely used at present on the highway road base, but the accessing of these materials will damage to the environment. In order to achieving the double benefit of economy and environmental protection, it can make full use of chromium slag to instead of gravel and has a broad application prospect as the semi-rigid base or subbase.

Hexavalent chromium (Cr(VI)) is the first category of heavy metal pollutants, it has strong oxidative toxicity and causes damage to human body, crops organism. Hexavalent chromium is also strong carcinogenic and mutagenic characteristics. Chromium and its compounds pollution is serious, especially in high carbon ferrochrome slag (hereinafter referred to as the chromium slag) pollution. Chromium slag is a kind of industrial waste residue, which has bigger harm of the environment, plants and animals and humans and is the world recognized solid waste that has bigger pollution threat, complex properties and difficult to deal with.

In order to strictly control the chromium pollution, China formulated multiple control standards of the hexavalent chromium and total chromium. Sewage comprehensive discharge standard of $\mathrm{Cr}(\mathrm{VI})$ in the industrial wastewater in our country is $0.5 \mathrm{mg} / \mathrm{L} \mathrm{[2].}$

It is the key as the applications of chromium slag to the road base or subbase that how to make use of chromium slag activity and avoid the instability of chromium slag. In this paper, using cement and lime as inorganic binder to stable chromium slag to get the best moisture contentand maximum dry density of stable body by the compaction test, improving the design of base material mixture on the basis of the optimum water content; Determine the unconfined compressive strength stability of body based on the optimal proportion, to provide feasible basis for the application of chromium slag in road base or subbase reasonably and effectively; Take the broken pieces of the stable body form the unconfined compressive strength test in 7 days ages, and determinate the Cr (VI) content in the states of water soluble, acid soluble and alkaline soluble, compare with the national standard to ensure it can be meet the requirements of the environmental indicators .

\section{TEST RAW MATERIALS}

Chromium slag: from a factory in Inner Mongolia chromium slag yards, appearance is brown-black. The test 
is refer to JTG E42-2005 [3], particle composition measured is shown in Table 1 , crush value is 20 . $7 \%$, the apparent density of $2.710 \mathrm{~g} / \mathrm{cm}^{3}$.

TABLE I. PARTICLES OF CHROMIUM SLAG

\begin{tabular}{|c|c|c|c|c|c|}
\hline Particle size(mm) & 9.5 & 4.75 & 2.36 & 0.6 & 0.075 \\
\hline Pass rate(\%) & 100 & 89.5 & 63.3 & 21.9 & 11.1 \\
\hline
\end{tabular}

Water: use laboratory of tap water, in line with our current standard "the health standard of drinking water" of GB5749 regulation.

Cement: use Jinyu brand P.O. 42.5, namely ordinary Portland cement concrete, its performance indexes after checking is shown in Table 2. Test is refer to JTGE302005 [4].

TABLE II. PERFORMANCE INDEXES

\begin{tabular}{|c|c|c|c|}
\hline \multirow{2}{*}{\multicolumn{2}{|c|}{$\begin{array}{c}\text { Fineness } \\
\text { (\%) }\end{array}$}} & \multicolumn{2}{|c|}{ Setting time(min) } \\
\hline & & Initial setting & Final setting \\
\hline \multicolumn{2}{|c|}{3.4} & 140 & 355 \\
\hline \multicolumn{2}{|c|}{ 3d Strength(MPa) } & \multicolumn{2}{|c|}{ 28d Strength(MPa) } \\
\hline Compressive & Bending & Compressive & \begin{tabular}{l|l} 
& Bending
\end{tabular} \\
\hline 24.2 & 4.3 & 47.9 & 7.9 \\
\hline
\end{tabular}

Lime: use Shanghai flower garden brand lime powder, white, chemical formula is $\mathrm{CaO}$, molecular weight is 56.08 , proportion is $3.25 \sim 3.38$, melting point is $2580^{\circ} \mathrm{C}$, boiling point is $2850^{\circ} \mathrm{C}$.

\section{TEST RESUlts AND ANALYSIS}

\section{A. The best moisture content and maximum dry density}

According to JTG E51-2009 [5], chromium slag belongs to the fine grading for its particle size is less than $5 \mathrm{~mm}$, using light compaction test standard, test tube volume is $997 \mathrm{~cm}^{3}$, hammering points 5 layer, each layer of hammer 27 times. According to the tentative test to determine the mixture of cement and lime measurement is $40 \%$, Dried sample moisture content is $0.684 \%$, Estimate the optimal moisture content is $16 \%$, Mixture density is $2.71 \mathrm{~g} / \mathrm{cm}^{3}$, Water content is $14 \%, 16 \%, 18 \%, 20 \%, 22 \%$. Main test data is shown in Table 3. Curves of relationship between water content and dry density (i.e.W $\sim \mathrm{P}_{\mathrm{d}}$ curve) on cement and lime stable chromium slag(i.e. cement stable body and lime stable body) are shown in Fig .1 and Fig .2.

TABLE III. THE MAIN TEST DATA

\begin{tabular}{|c|c|c|c|c|c|c|}
\hline & Test period & 1 & 2 & 3 & 4 & 5 \\
\hline \multirow{3}{*}{$\begin{array}{c}\text { Cement } \\
\text { stable } \\
\text { body }\end{array}$} & $\begin{array}{c}\text { Dry density } \\
P_{\mathrm{d}}\left(\mathrm{g} / \mathrm{cm}^{3}\right)\end{array}$ & 1.987 & 2.032 & 2.014 & 1.872 & 1.844 \\
\hline & $\begin{array}{c}P_{\mathrm{d}}(\mathrm{Va}=\mathbf{0}, \\
\left.\mathrm{g} / \mathrm{cm}^{3}\right)\end{array}$ & 2.080 & 2.057 & 2.025 & 1.947 & 1.879 \\
\hline & $\begin{array}{c}\text { Average } \\
\text { moisture } \\
\text { content(\%) }\end{array}$ & 11.2 & 11.7 & 12.5 & 14.4 & 16.3 \\
\hline \multirow{3}{*}{$\begin{array}{l}\text { Lime } \\
\text { stable } \\
\text { body }\end{array}$} & $\begin{array}{c}\text { Dry density } \\
P_{d}\left(\mathrm{~g} / \mathrm{cm}^{3}\right) \\
\end{array}$ & 2.041 & 2.042 & 1.989 & 1.920 & 1.849 \\
\hline & $\begin{array}{c}P_{d}(\mathbf{V a}=0, \\
\left.g / \mathbf{c m}^{3}\right)\end{array}$ & 2.152 & 2.059 & 1.993 & 1.936 & 1.877 \\
\hline & $\begin{array}{c}\text { Average } \\
\text { moisture } \\
\text { content(\%) }\end{array}$ & 9.6 & 11.7 & 13.3 & 14.8 & 16.4 \\
\hline
\end{tabular}

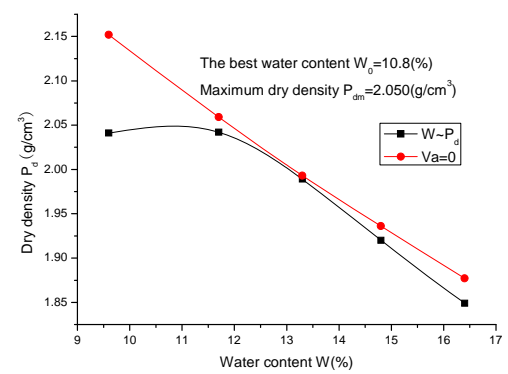

Figure 1. $\quad \mathrm{W} \sim \mathrm{P}_{\mathrm{d}}$ curve of lime stable body

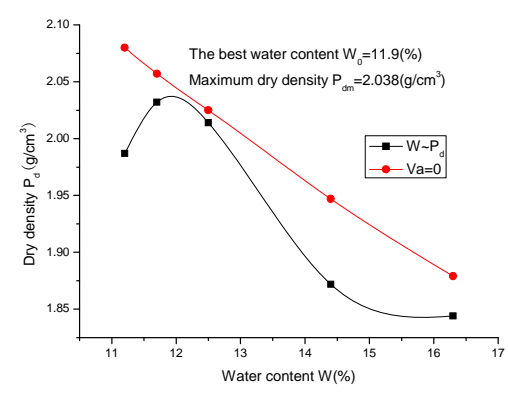

Figure 2. $\mathrm{W} \sim \mathrm{P}_{\mathrm{d}}$ curve of cement stable body

It can be seen from Fig .1 and Fig .2 that the best water content $\left(\mathrm{W}_{0}\right)$ and the maximum dry density $\left(\mathrm{P}_{\mathrm{dm}}\right)$ of cement stable body are $11.9 \%$ and $2.038 \mathrm{~g} / \mathrm{cm} 3$, and that of lime stabilized body are $10.8 \%$ and $2.050 \mathrm{~g} / \mathrm{cm} 3$. It is easy to achieve from $\mathrm{W} \sim \mathrm{Pd}$ curve of cement stable body that the influence of water content to dry density is very big, the estimate main area of influence the water content is $9.0 \%$ to $15.0 \%$ and the peak is obvious; For $\mathrm{W} \sim \mathrm{Pd}$ curve of lime stabilized body, the influence of water content of dry density is bigger, while the main influence area of the water content to dry density is unable to estimate and the peak is not easy to get.

\section{B. Unconfined compressive strength}

According to the best water content determined by the compaction test, the optimum mixture ratio is get and shown in Table 4. Using static pressure molding, forming a $100 \times 100 \mathrm{~mm}$ specimens for fine grading chromium slag, and specimens after forming are put into the standard curing indoor whose the temperature $\left(20 \pm 2{ }^{\circ} \mathrm{C}\right)$, relative humidity more than $95 \%$ to one day ago of curing age, flooding one day before the test. Using hydraulic press to do the unconfined compressive strength test, loading rate of press is $1 \mathrm{~mm} / \mathrm{min}$. The number of specimens in each group is not less than 9 , variation coefficient of test results $\left(C_{v}\right)$ is less than $10 \%$.Test results are shown in Table 5.

TABLE IV. OPTIMUM MIXTURE RATIO

\begin{tabular}{|c|c|}
\hline Mixture & Best mixture ratio \\
\hline Cement: chromium slag: water & $40: 60: 11.9$ \\
\hline Lime: chromium slag: water & $40: 60: 10.8$ \\
\hline
\end{tabular}


TABLE V. UNCONFINED COMPRESSIVE STRENGTH

\begin{tabular}{|c|c|c|c|c|c|c|}
\hline & \multicolumn{2}{|c|}{ Cement stable body } & \multicolumn{3}{|c|}{ Lime stable body } \\
\hline Age(d) & 7 & 14 & 28 & 7 & 14 & 28 \\
\hline $\begin{array}{c}\text { Unconfined compressive } \\
\text { strength(MPa) }\end{array}$ & 2.5 & 3.7 & 5.2 & 0.02 & 0.1 & 0.3 \\
\hline variation coefficient (\%) & 5.2 & 5.9 & 4.7 & 7.0 & 6.5 & 6.8 \\
\hline
\end{tabular}

From Table 5, the variation coefficient $\left(C_{v}\right)$ of the experimental data is less than $10 \%$, which shows that the selection of test data is feasible; Unconfined compressive strength in different instars of Cement stable body is greater than that of lime stable body, especially the strength of 28 days. But as Pozzolanic reaction is different from cement hydration, the structural strength provided by lime stable body is not better than cement stable body, and therefore using less alone. And on other stabilization process, it can get extra stability improvement add a small amount of cement or fly ash with lime to solid waste [6].

\section{Stable effect}

\section{a) Chromium Standard Curve Drawing}

In accordance with the method prescribed by the (GB 7467-87) to text, correction data in standard series by blank test is shown in Table 6.

TABLE VI. CORRECTION DATA IN STANDARD SERIES

\begin{tabular}{|c|c|c|c|c|c|c|c|c|c|}
\hline Serial number & 1 & 2 & 3 & 4 & 5 & 6 & 7 & 8 & 9 \\
\hline $\begin{array}{c}\text { Content of the } \\
\text { chrome( } \boldsymbol{\mu g})\end{array}$ & 0.00 & 0.20 & 0.50 & 1.00 & 2.00 & 4.00 & 6.00 & 8.00 & 10.00 \\
\hline $\begin{array}{c}\text { Absorbance } \\
\left(\mathbf{A - A} \mathbf{A}_{\mathbf{0}}\right)\end{array}$ & 0.001 & 0.003 & 0.004 & 0.009 & 0.028 & 0.041 & 0.058 & 0.079 & 0.105 \\
\hline
\end{tabular}

$\mathrm{Cr}(\mathrm{VI})$ content $(\mu \mathrm{g})$ as the abscissa, the difference between standard solution absorbance $(\mathrm{A})$ and the reagent blank liquid absorbance $\left(\mathrm{A}_{0}\right)$ as the ordinate standard to make the results to curve plotting, using least square method for linear fitting, chromium standard curve of the linear regression equation is obtained for the equation (1).

$Y=0.0101 X+0.0009\left(\mathrm{R}^{2}=0.9962\right)$

Chromium standard curve and test values is shown in Fig .3, the equation (1) linear correlation is higher, which can be used for calculating $\mathrm{Cr}(\mathrm{VI})$ content.

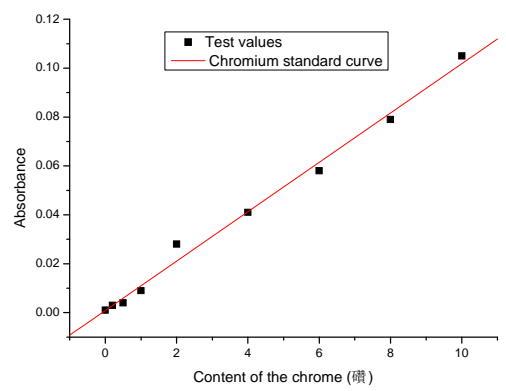

Figure 3. $\quad \mathrm{W} \sim \mathrm{P}_{\mathrm{d}}$ curve of cement stable body b) Discriminant of stable effect

Take chromium slag and the stable body block from the unconfined compressive strength test of 7 days, crush and dry it, and through it out of 150 mesh screen square hole, put it in a constant temperature drying oven (temperature is $105^{\circ} \mathrm{C}$ ) in 4 hours then take out and set aside.Use the HJT 301-301 [7] to determinate the concentration of $\mathrm{Cr}(\mathrm{VI})$ in the solidified body. The analysis method of $\mathrm{Cr}(\mathrm{VI})$ is (GB 7467-87) [8].

By chromium slag, cement stable body and lime stably body in different dissolved state absorbance and chromium standard curve regression equation (2.1) to $\mathrm{Cr}$ (VI) concentration of leaching in Table 7 , stable effect of different dissolved states is shown in Fig .4.

TABLE VII. CR (VI) LEACHING CONCENTRATION (MG/L) OF DIFFERENT DISSOLVED STATE

\begin{tabular}{|c|c|c|c|}
\hline Soluble state & 1 & 2 & 3 \\
\hline Chromium slag & 0.805 & 0.508 & 0.246 \\
\hline Cement stable body & 0.152 & 0.058 & 0.112 \\
\hline Lime stable body & 0.078 & 0.132 & 0.142 \\
\hline National standard & 0.5 & 0.5 & 0.5 \\
\hline
\end{tabular}

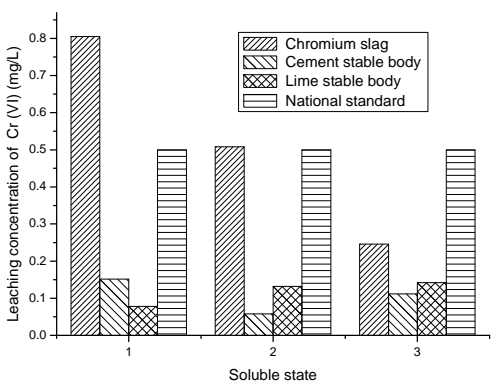

Figure 4. $\mathrm{W} \sim \mathrm{P}_{\mathrm{d}}$ curve of cement stable body

According to the Table 7 and Fig .4, leaching concentration of $\mathrm{Cr}(\mathrm{VI})$ in acid soluble and water soluble states of chromium slag is out national standard, while that in alkaline soluble state is qualified; Chromium slag after cement stable and lime stable, leaching concentration of $\mathrm{Cr}(\mathrm{VI})$ in three state are greatly reduced and all up to the national discharge standard.

The mechanism of Cement stability is cement formed a hard stone structure that close to rock properties and give priority to with hydrated calcium silicate gel after the cement hydration. Chromium slag was mixed with cement matrix, its hexavalent chromium was packaged or adsorption by hydrated calcium silicate gel (SCH) under the action of physical and chemistry; Another product of cement hydration is ettringite (AFt), it can form solid solution with hexavalent chromium in waste, and also reduce the mobility of the hexavalent chromium in waste and the cement matrix; Another point is that due to the structure of the cement has gel holes and a small amount of porosity, therefore it is pore impervious under atmospheric pressure, chrome enclosed in cement could not be dissolved and spread out [9].

The mechanism of lime stability is lime is used as a stabilizer to improve mixture of $\mathrm{pH}$ value, while chromium slag has a strong alkaline (PH is10 13) [10], and it makes the $\mathrm{Cr}(\mathrm{VI})$ of stable body is not easy to be 
released into the natural environment by physical and chemical reaction in acidic state.

\section{CONCLUSION}

By the compaction test, it can be gotten that the optimum water content $\left(\mathrm{W}_{0}\right)$ of cement and lime stable chromium slag are $11.9 \%$ and $10.8 \%$, and optimal mixture ratio is easy to achieve based on it.

On the basis of the optimal mixture ratio, cement stable chromium slag can better meet using performance requirements as the road base materials when inorganic binder is used alone; Mechanical performance of lime stable chromium slag is a bit weak, while it can get extra stability improvement to plus a small amount of cement or fly ash.

Cr (VI) leaching concentration of chromium slag in water soluble and acid soluble state are beyond the integrated wastewater discharge standard in China, it needs to repeat leaching in order to achieve the goal of free-pollution disposal; The effect of chromium slag stabilized by cement and lime is obvious, and $\mathrm{Cr}$ (VI) concentration of leaching under each medium can satisfy the requirements of national standard.

As industrial waste residue of chromium slag, it can be formed the semi-rigid base materials after the stability of the inorganic binder, applying reasonably and effectively in road base is not only reduce the pollution of the waste chromium slag and develop its comprehensive utilization, but also realize the double benefit of economy and environment protection.

\section{REFERENCES}

[1] Lihan Li, Nanlu Zhang. "Road building materials”. Beijing: People's traffic press, 2006.

[2] "Environmental science big dictionary editorial board,”Environmental science. Beijing. China environmental science press, 1991, pp. 217-219.

[3] JTG E42-2005, "Highway engineering aggregate test procedures".

[4] JTG E30-2005, "Highway engineering cement and concrete test procedures”.

[5] JTJ 051-2009, "Highway engineering stability of inorganic binder materials testing procedures”.

[6] Zhitong Yao. "Solid waste recycling utilization of fly ash," Zhejiang university, 2010.

[7] HJT 301-2007,“Chromium slag pollution environmental protection technical specification (interim)”.

[8] GB 7467-87,“Water quality determination of hexavalent chromium diphenyl carbonyl 2 hydrazine spectrophotometric method”.

[9] Jun Gu. "Chromium residue detoxification and stability,”Chongqing: School of materials science and engineering, Chongqing university ,2006.

[10] Chunli Chen, Guoyuan Lei. "From the research progress of separation and recovery of chromium chromium slag," Journal of comprehensive utilization of mineral resources,vol. 5, Mar. 2001, pp. 3-6. 